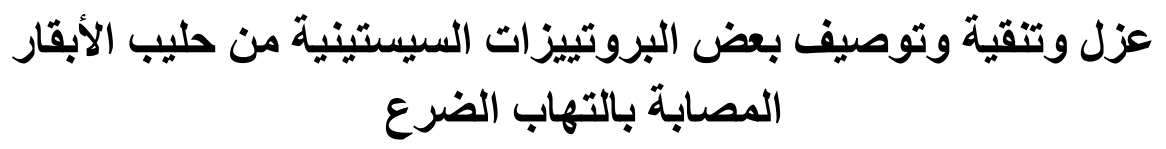

\title{
Isolation, Purification, And Characterization Of Some Cystein Proteases From Bovine Mastites Milk
}

\author{
كفاح سعيد عباس دوش \\ قسم علوم الاغذية و التقانة الاحيائية / كلية الزر اعة / جامعة بغداد
}

\section{K.S. Doosh}

Dept. of Food Science and Biotechnology / College of Agriculture/ University of Baghdad

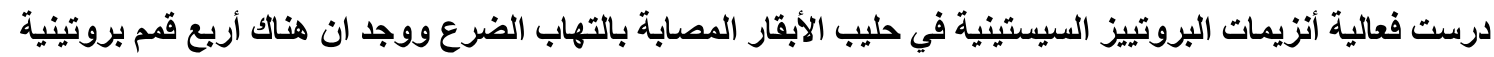

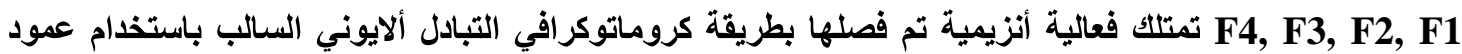

DEAE- Cellulose

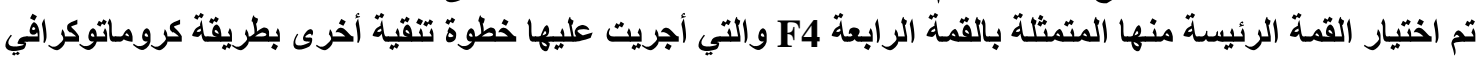

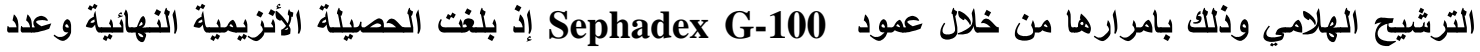
مرات التقية لها 31.81 \% و 46.66 مرة على التوالي ـ اجري الترحيل الكهربائي في هلام متعدد الاكريل امايد

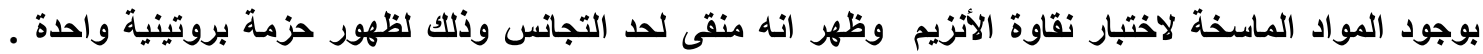
أظهرت نتائج توصيف الأنزيم ان وزنه ألجزيئي يقدر (31000 و

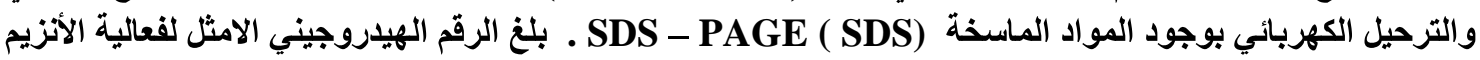
6.0 وتراوح المدى الامثل لثباته بيـن 4.5 - 6.5 واظهر الأنزيم أقصى فعالية عند درجة حرارة 45 م ـ أشارت نتيجة الألئ

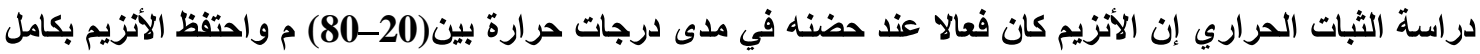

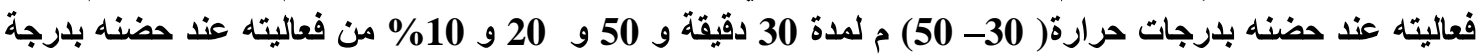

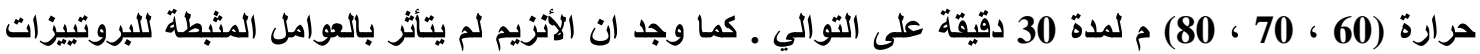

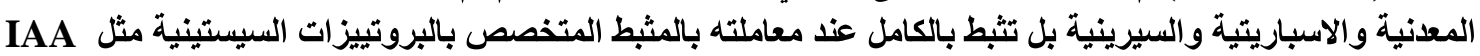

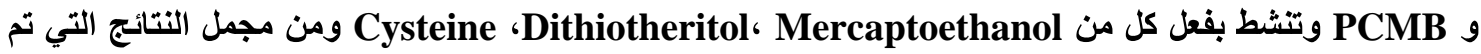

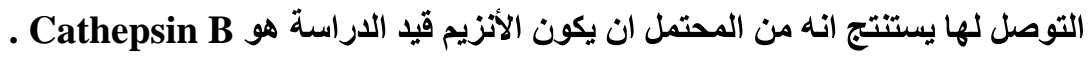

\section{Abstract}

Proteolytic activity of cysteine proteases were studied in bovine mastitis milk, four fractions designated as F1,F2,F3,F4 with cysteine protease activity were separated from leukocytes cell by ion- exchange Chromatography through DEAE-Cellulose The most active fraction F4 was selected for further purification utilizing gel filtration Chromatography on Sephadex G-100 column it has been found that F4 most likely being cathepsin B. purification folds and the enzyme yield was 46.66 and $31.81 \%$ respectively - polyacrylamide gel electrophoresis test indicated that the enzyme has been purified to homogeneity by giving a single band. The results of enzyme characterization showed that the molecular weights were 31000 and 30000 Daltons as 
determined by gel filtration and electrophoresis methods in present of reducing agent SDS- PAGE respectively. The optimum pH for the enzyme activity was 6.0 and it was stable at $\mathrm{pH}$ values ranged between 4.5 - 6.5 .The enzyme exhibited the maximum activity at $45 ? \mathrm{C}$ and the enzyme retained its entire activity over $30 \mathrm{~min}$ incubation at $30-50 \mathrm{C}$ and it retained $(50,20,10) \%$ of its entire activites over $30 \mathrm{~min}$ incubation at $(60,70,80) \mathrm{C}$ respectively. From this results and results observed from the effect of inhibitor and activator reagents we suggest that enzyme $\mathrm{F} 4$ possibly belonged to cathepsin $B$.

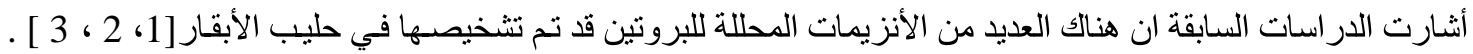

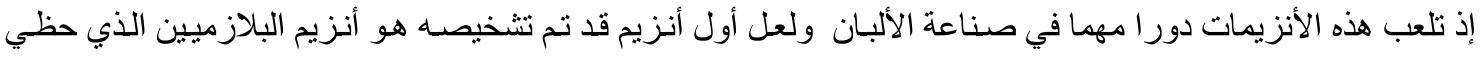

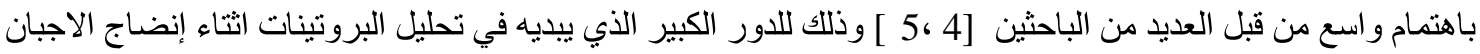

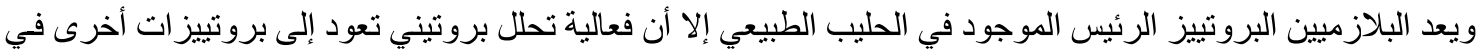

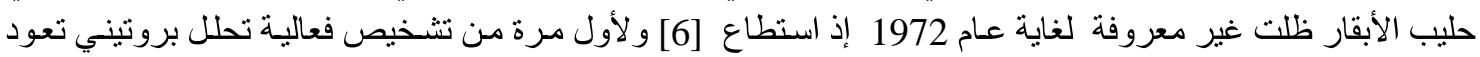

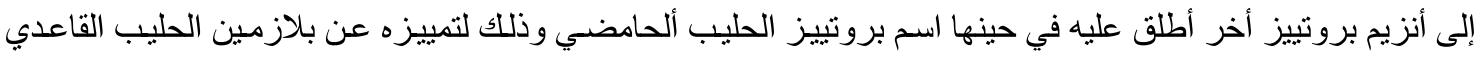

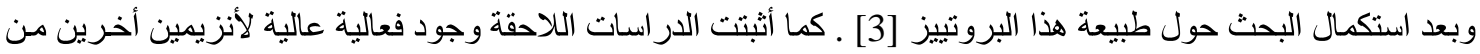

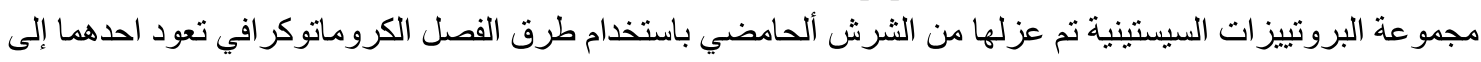

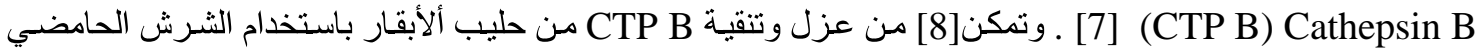

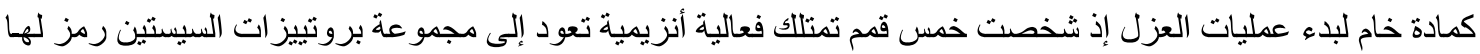
ع ع V, F IV, F III, F II, F I

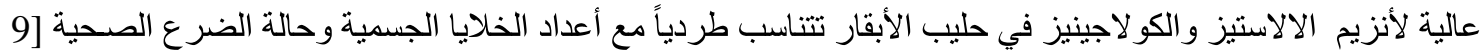

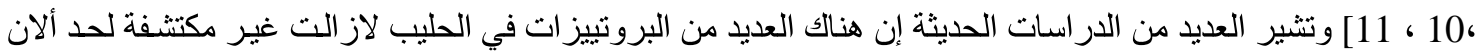

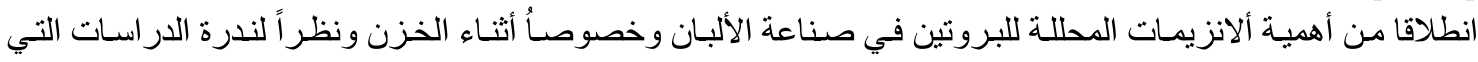

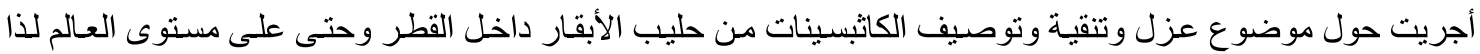

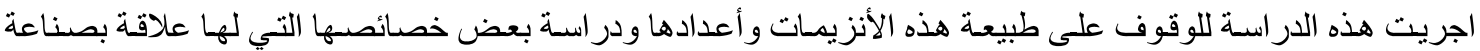

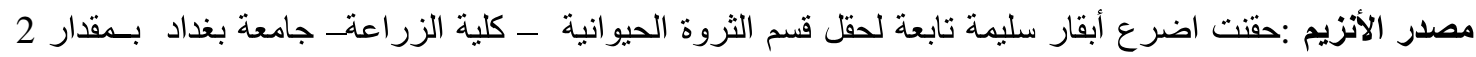

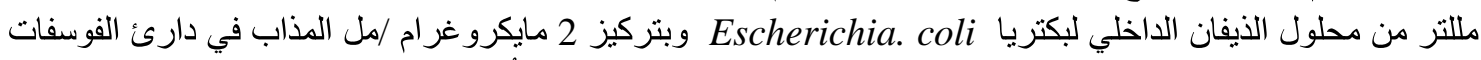

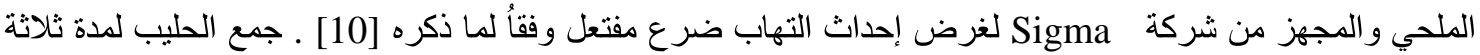

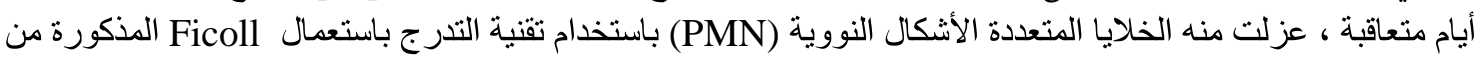

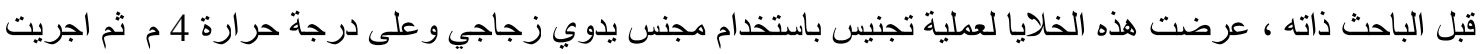

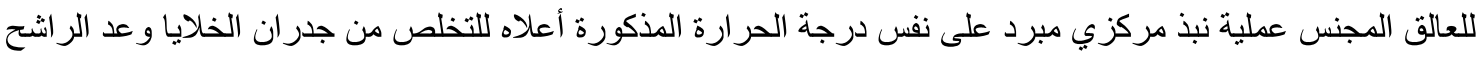

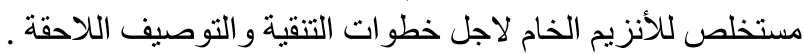

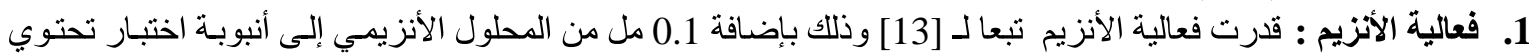

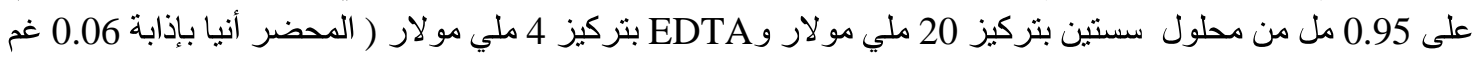

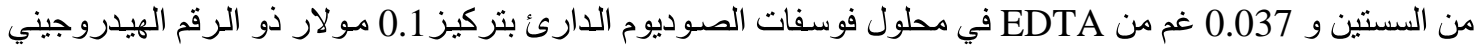

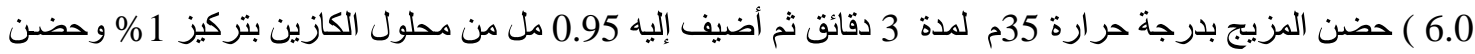

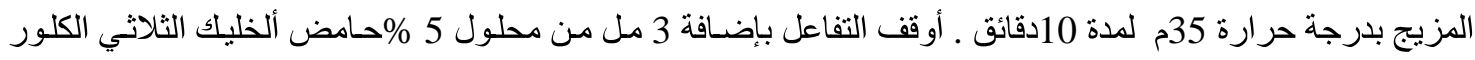

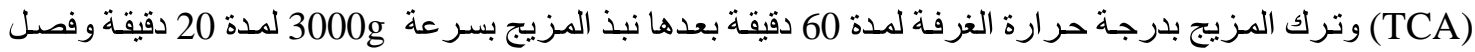

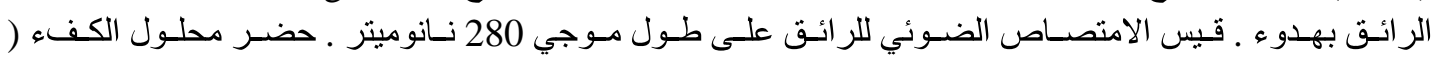

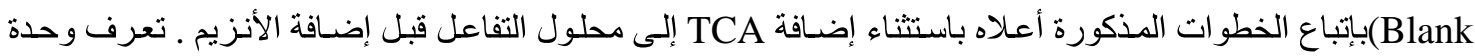


الفعالية التحللية بأنها كمية الأنزيم التي تزيد الامتصاصية وحدة واحدة بطول موجي 280 نانوميتر في الدقيقة الواحدة

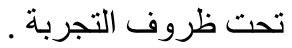

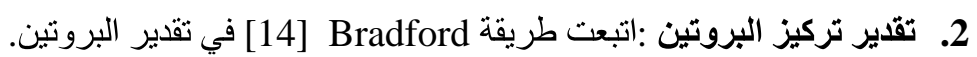

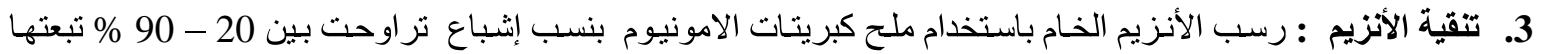

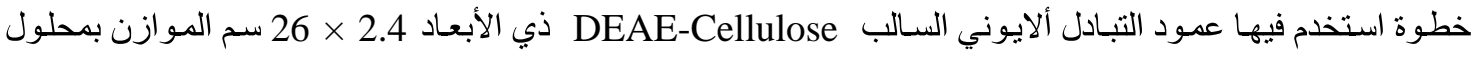

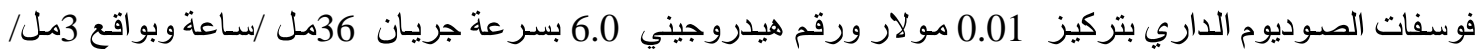

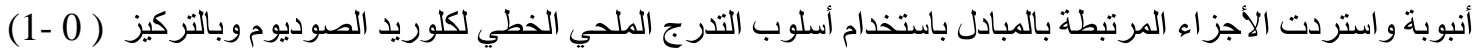

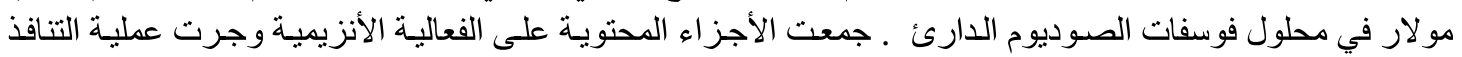

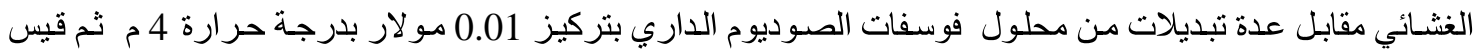

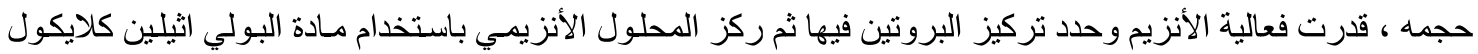

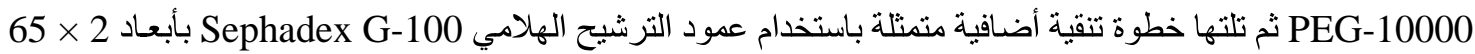

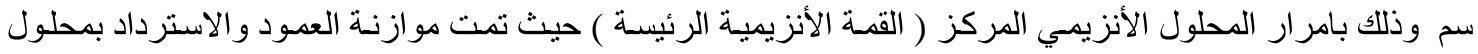

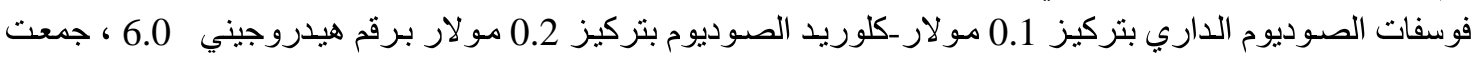

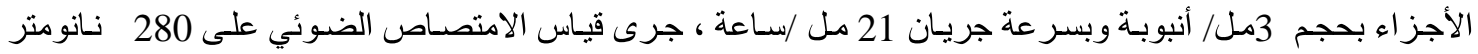

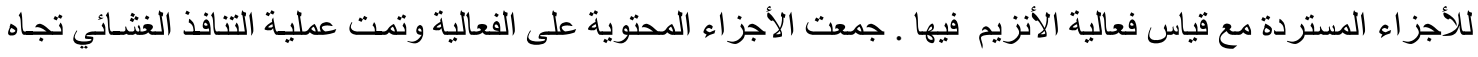

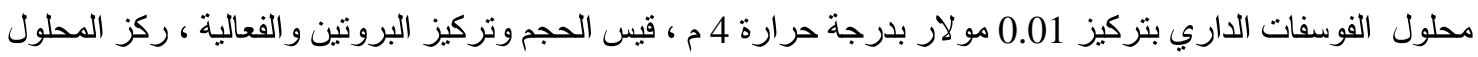

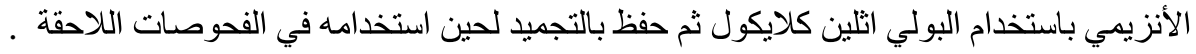

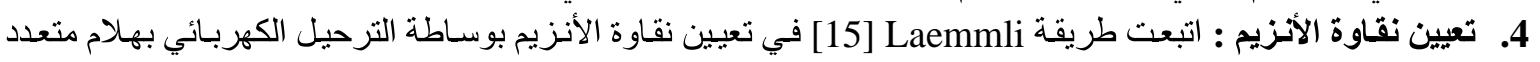

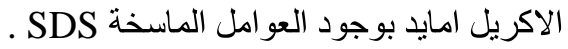

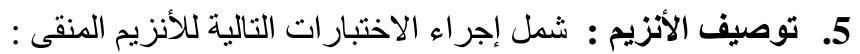

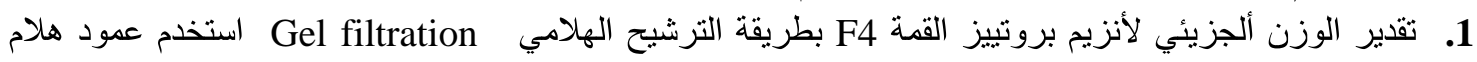

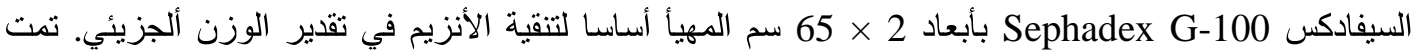

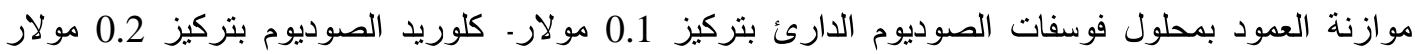

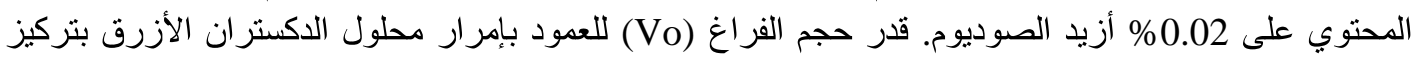

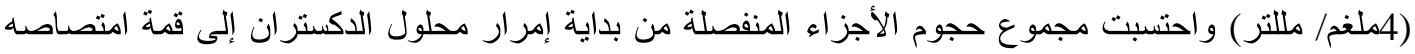

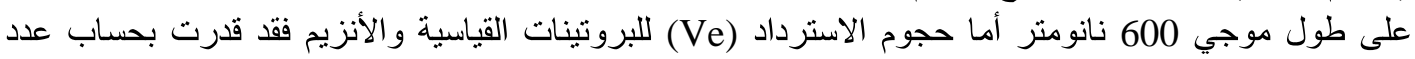

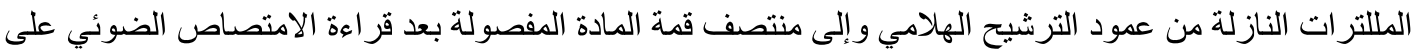

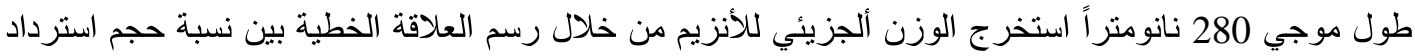

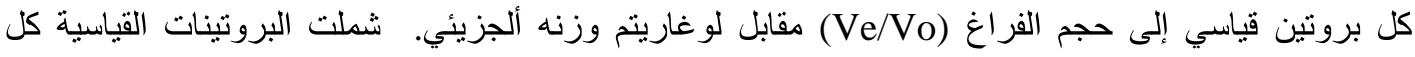

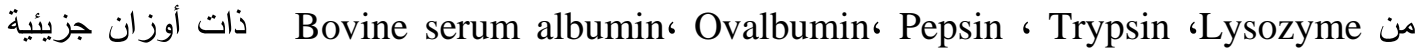

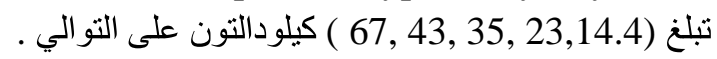

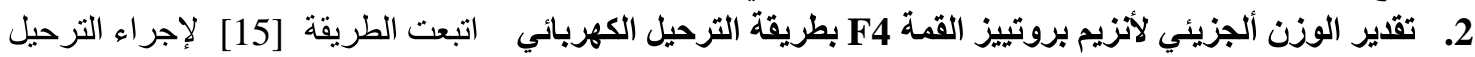

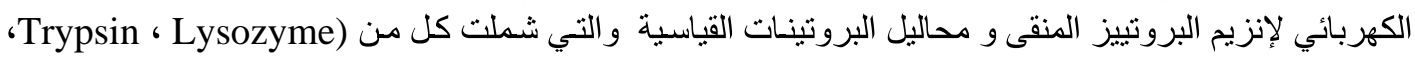
( $\gamma$-Globulin ،Transferrin، Collagenase(A,B)، Bovine serum albumin

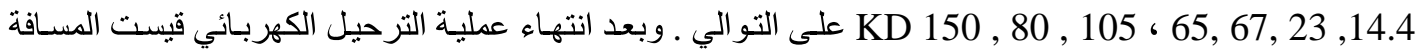

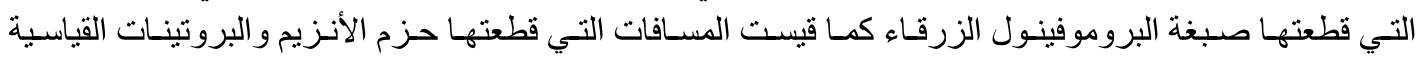

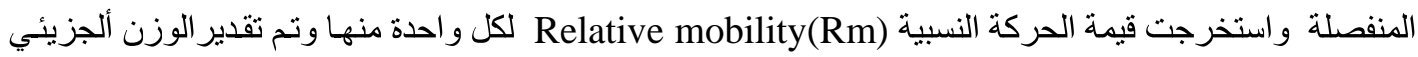

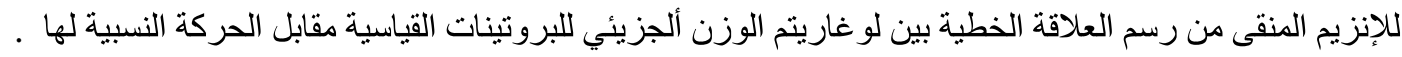

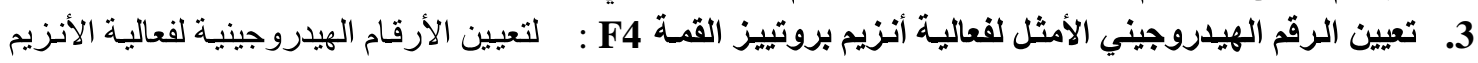

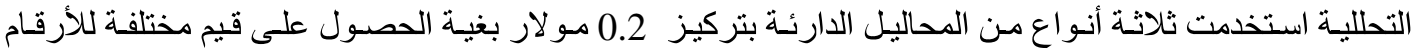

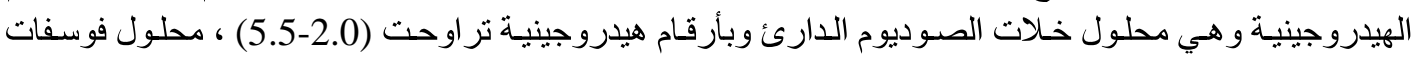

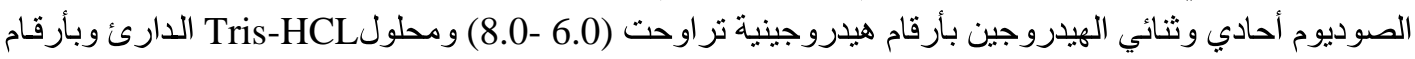

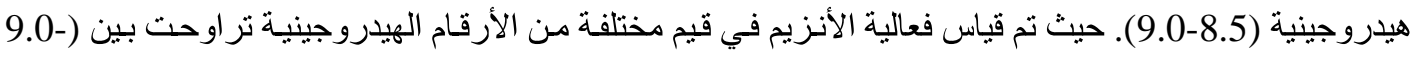


2.0) باستخدام الكازين كمـادة للتفاعل بدرجة حرارة 37 م لمدة 10 دقائق وحسب [13] ثم رسمت العلاقة بين

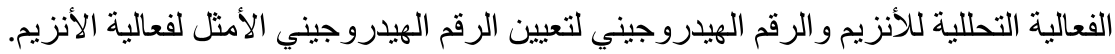

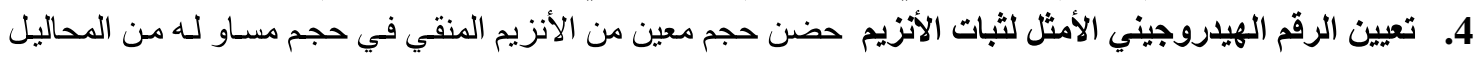

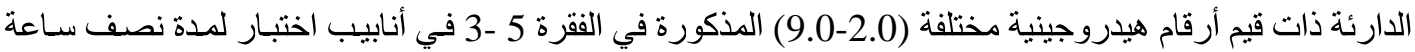

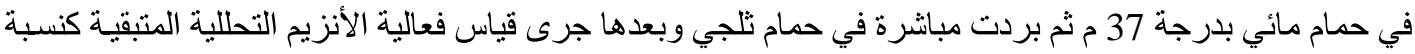

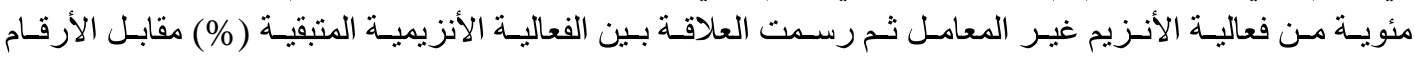

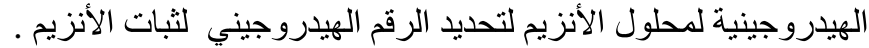

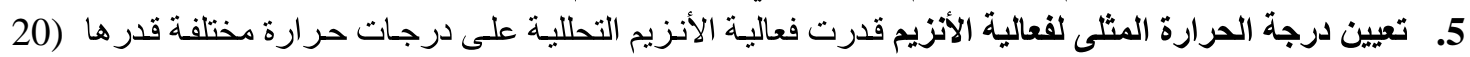

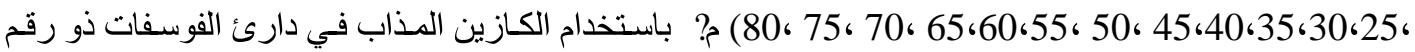

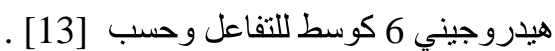

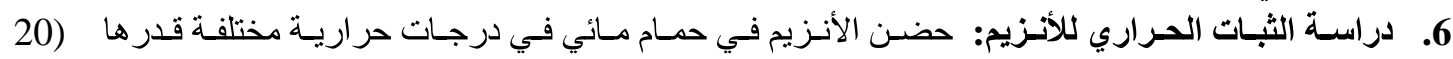

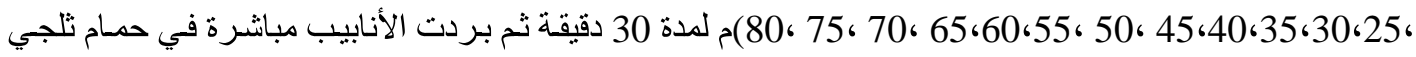

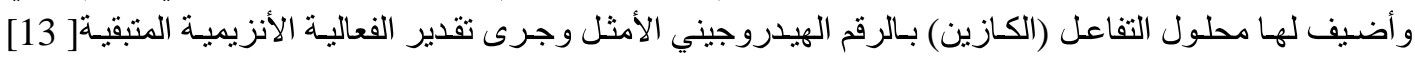

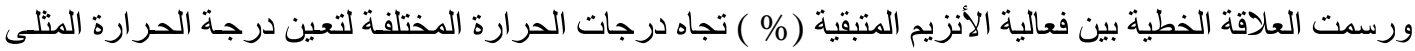
الثبات الإنزيم .

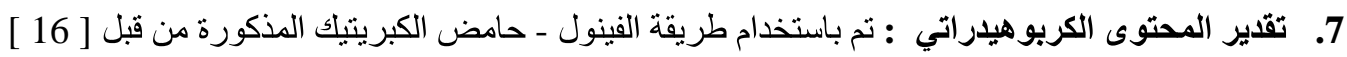
8.

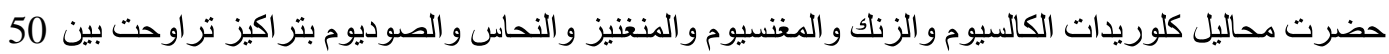

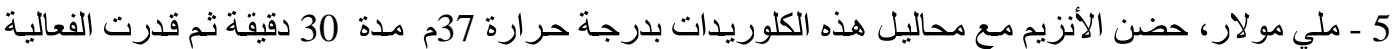

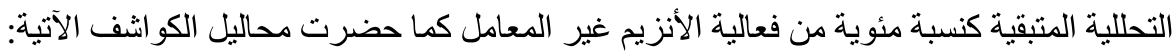

Pepstatin A (1mM );1,10- phenanthroline (10mM); Cysteine (10mM); Ethylene DiaminTetraacetic Acid (EDTA) (2mM) ; 2-Mercaptoethanol (10mM); Dithiotheritol (DTT)(10mM); Phenyl Methyl Sulphonil Fluoride (PMSF) (1mM); Iodo Acetic Acid (IAA) $(0.1 \mathrm{mM})$; Soybean trypsin inhibitor(SBTI) $(0.125-0.250 \mathrm{mg} / \mathrm{ml})$; 6-minoHexanoic Acid (6-AHA) ( 120mM ); P-chloromercurbenzoate (PCMB) (1mM).

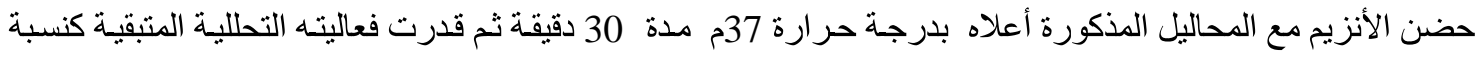

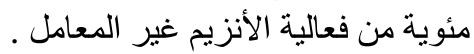

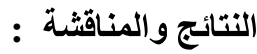

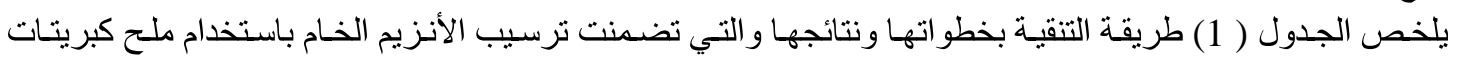

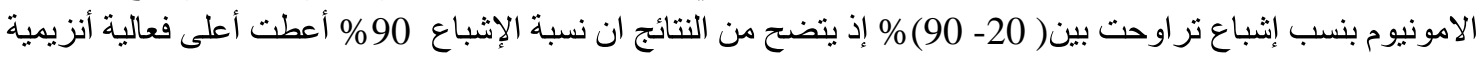

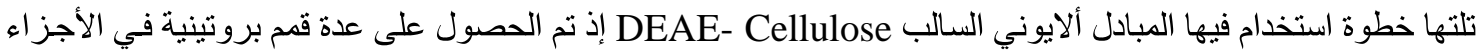

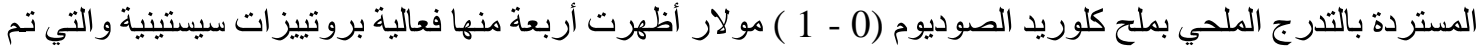

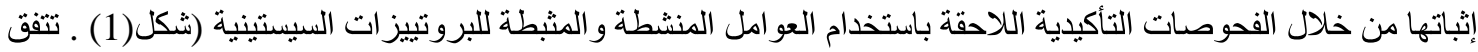

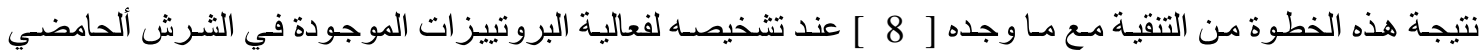

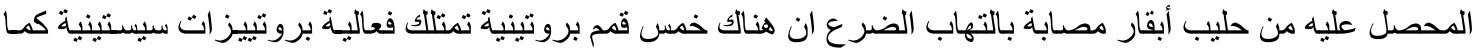

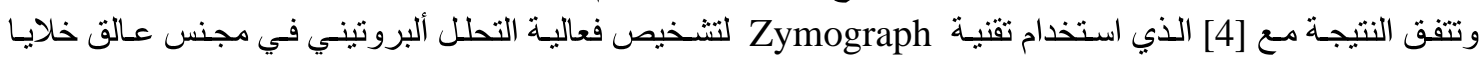

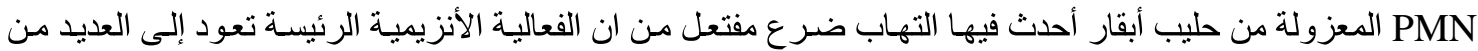

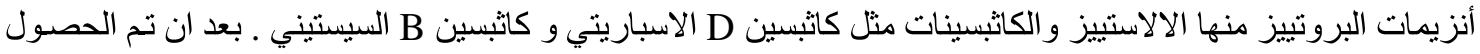

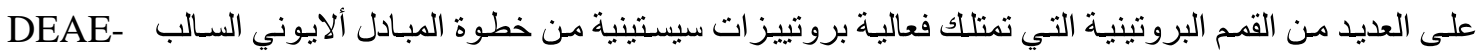
Cellulose

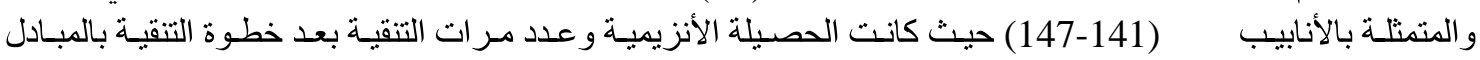

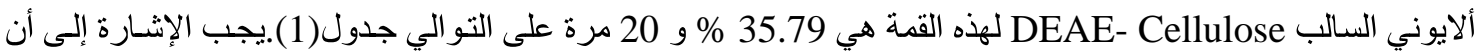

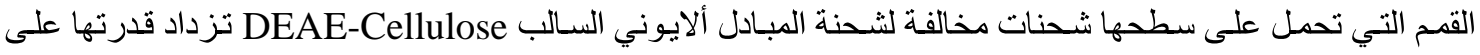

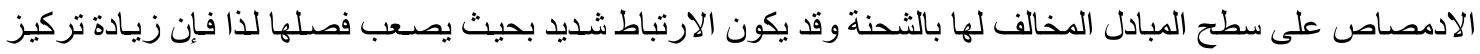


الملح في دارئ الاسترداد ساعد في عملية فصل مثل هذه البروتينات. وتعد طريقة التبادل الأيوني من الطرق الملائمسة في

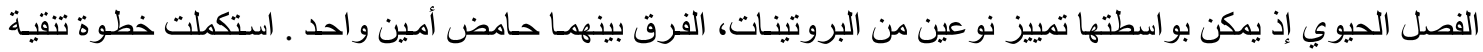

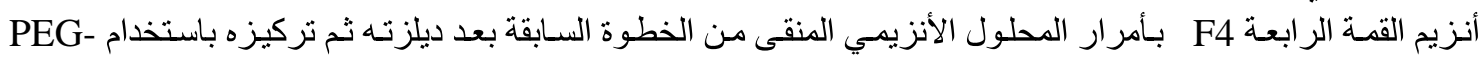

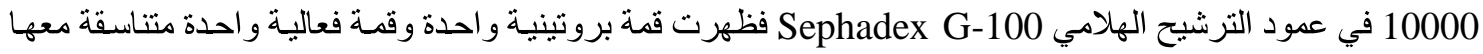

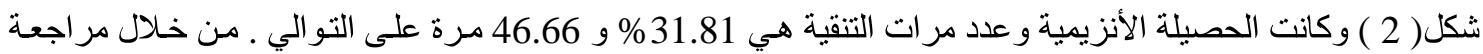

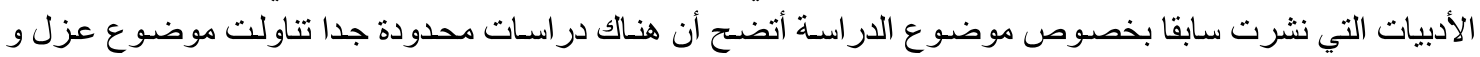

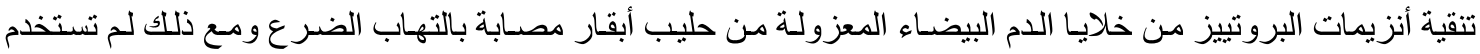

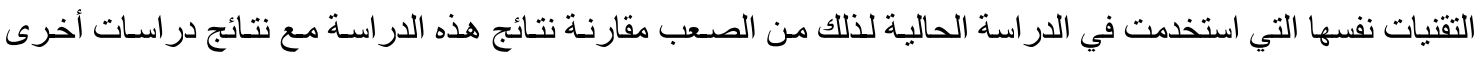

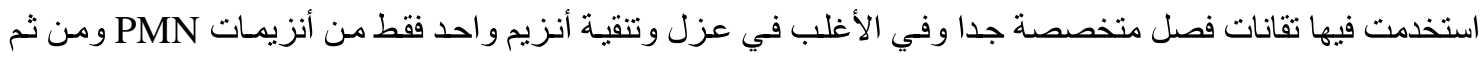

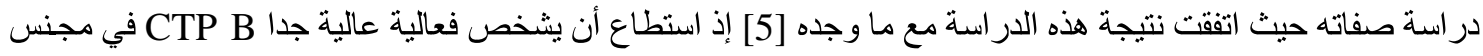

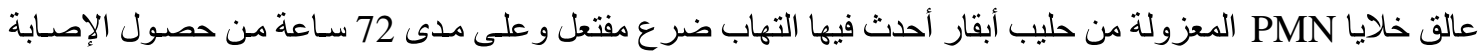

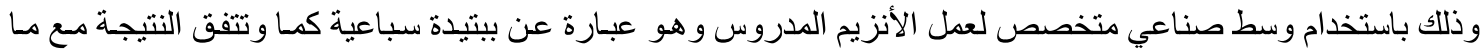

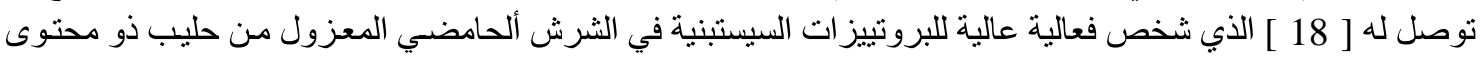

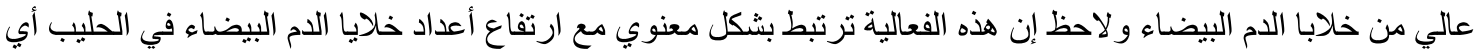

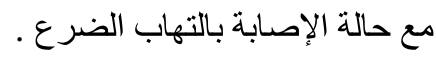


جدول (1) : خطوات تنقية انزيم البروتييز للقمة F4 المعزول من خلايا PMN المعزولة من حليب أبقار أحلث فيها التهاب ضرع.

\begin{tabular}{|c|c|c|c|c|c|c|c|}
\hline الأنزيلة & عرات & الفعالية & 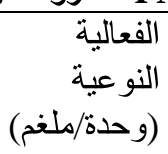 & البروتيز & (وحدة/مل) & (مل) & خطو ات التنقية \\
\hline 100.00 & 1.00 & 1056 & 30.00 & 0.40 & 12 & 88 & المستخلص الخام \\
\hline 75.00 & 3.42 & 792 & 102.85 & 0.35 & 36 & 22 & 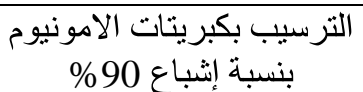 \\
\hline 35.79 & 20.00 & 378 & 600.00 & 0.03 & 18 & 21 & $\begin{array}{c}\text { التبادل ألايوني السالب } \\
\text { DEAE- cellulose } \\
\text { F4 القزيم بروتييز القمة }\end{array}$ \\
\hline 31.81 & 46.66 & 336 & 1400.00 & 0.02 & 28 & 12 & 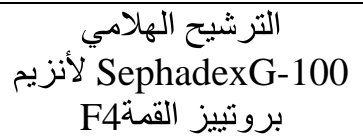 \\
\hline
\end{tabular}

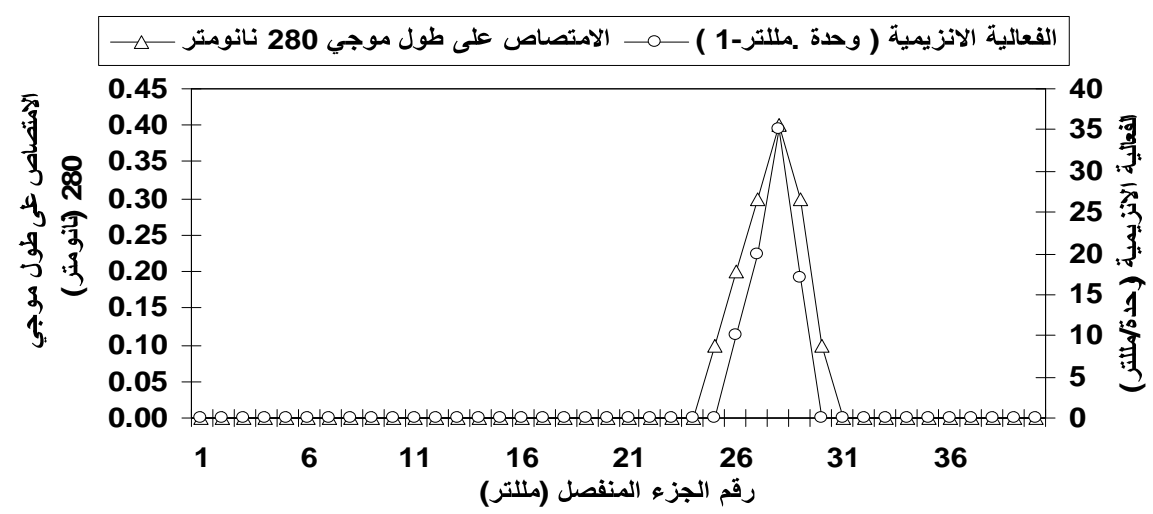

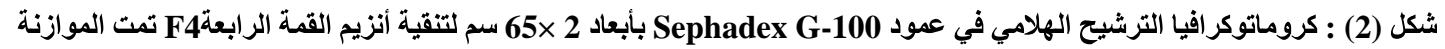

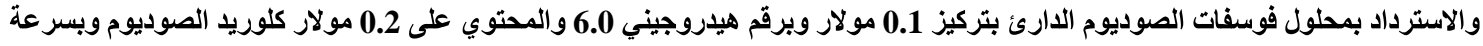

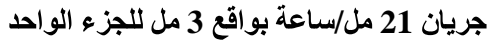

اختبار نقاوة الأنزيم

أشتارت نتائج الترحيل الكهربائي لأنزيم القمة الرابعة F4 خلال مر احل التنقية إلى إن الأنزيم الذي تمت تتقيته على عمود

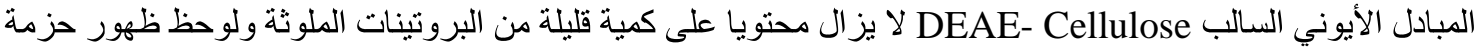

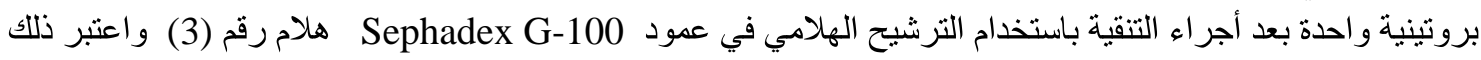

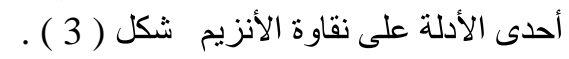




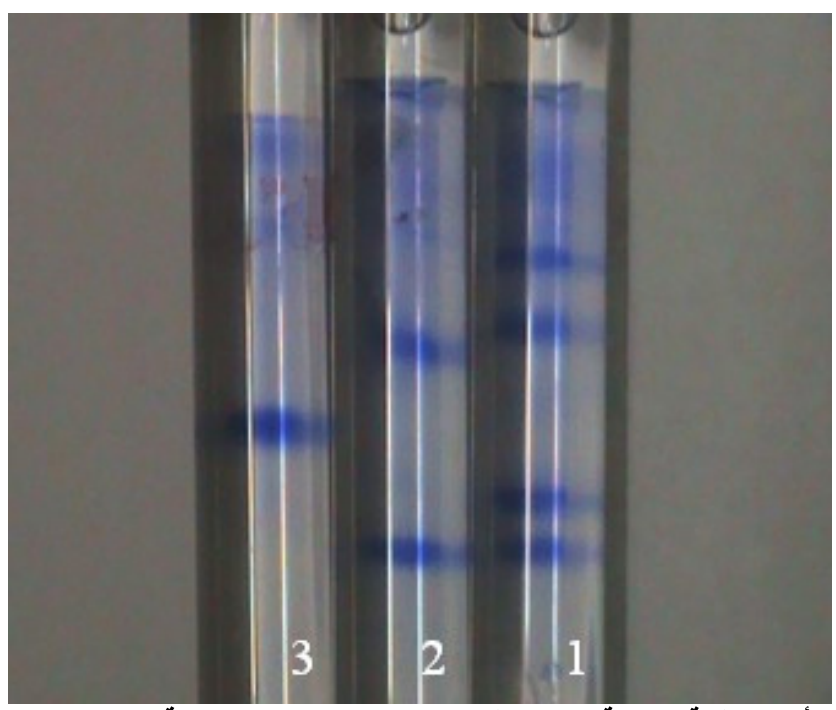

شكل(3) : الترحيل الكهربائي أنزيم القمة الرابعة F4 المنقى من خلايا PMN المعزولة من حليب الضرع المصاب في هلام متعدد الاكريل امايد بوجود العوامل الماسخة للبروتين إذ يمثل:

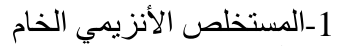

2-1الأنزيم المسترد بعد خطوة التبادل الأيوني بوساطة (DEAE - Cellulose)

3-3 الأنزيم المسترد بعد خطوة الترشيح الهلامي بوساطة (100 - Sephadex G )

توصيف الأنزيم

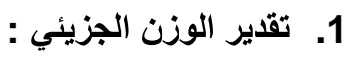

قدر الوزن ألجزيئي لأنزيم القمة الرابعة F4 بطريقة الترشيح الهلامي فبلغت قيمته 31000 دالتون شكل (4 ) كما أمكن

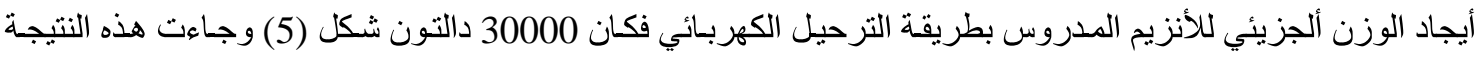

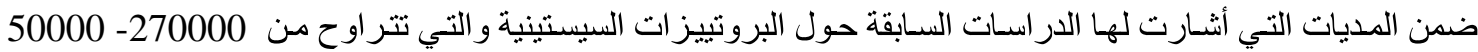

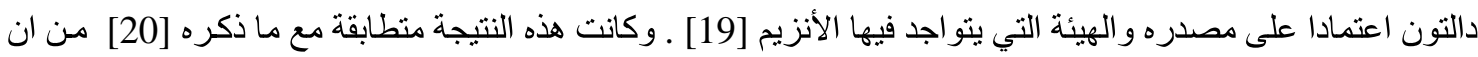

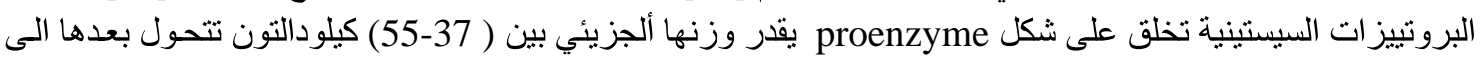

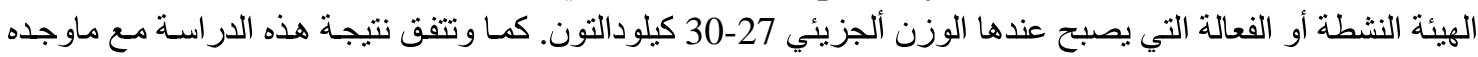

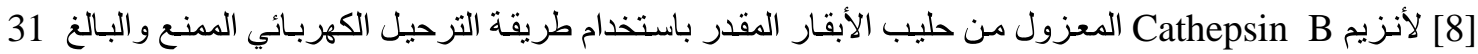

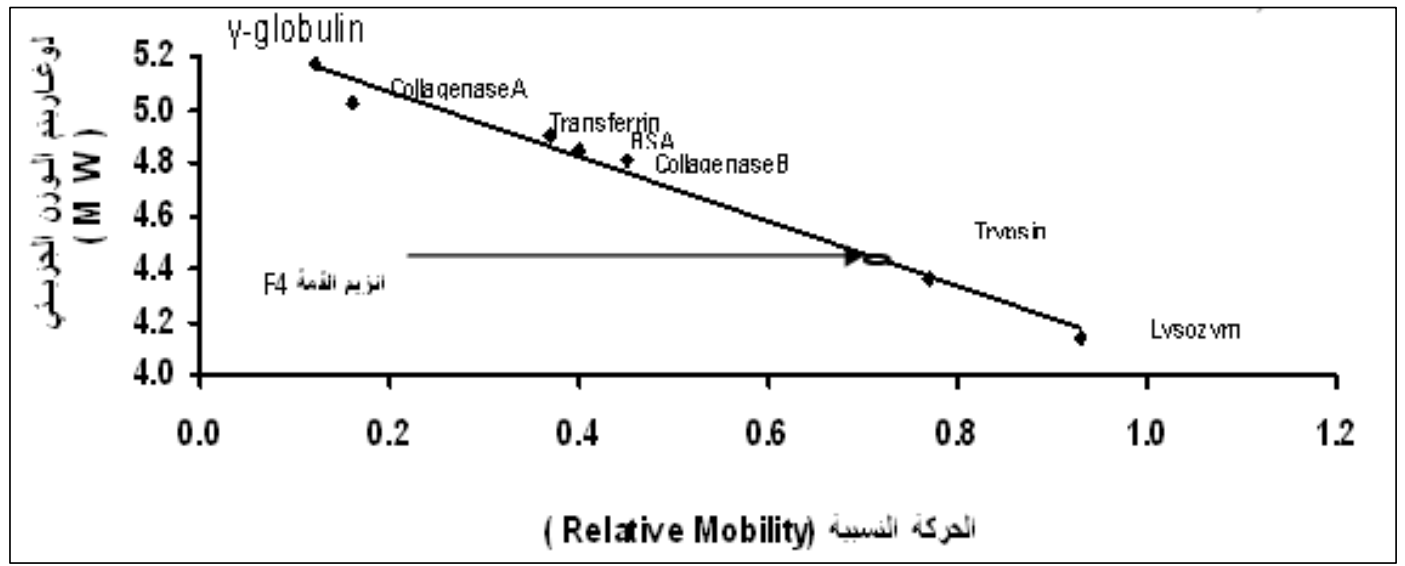




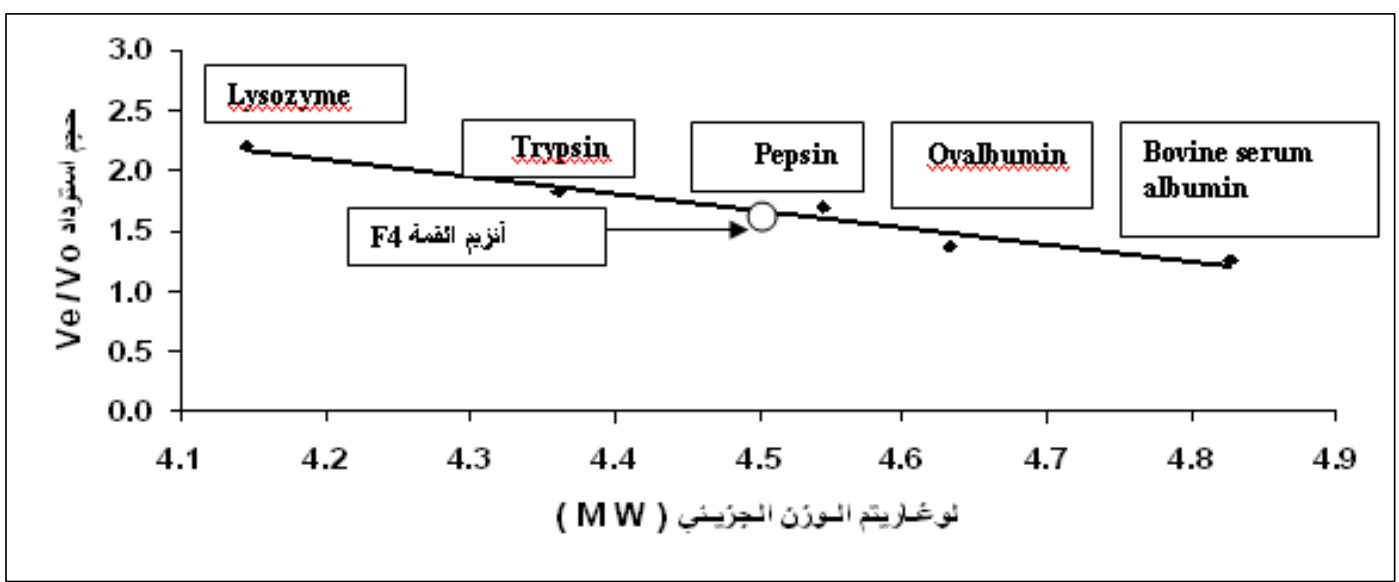

شكل(5) : المنحنى القياسي لتقدير الوزن ألجزيئي لأنزيم القمة الرابعة F4 المنقى من خلايا PMN بطريقة الترحيل الكهربائي بهلام متعدد الاكريل امايد بوجود العوامل الماسخة للبروتين العين العزين

\section{2.تعيين الرقم الهيروجيني الامثل لفعالية وثبات الأنزيم :}

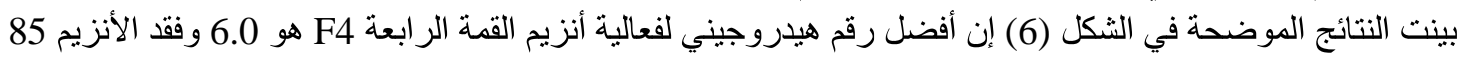

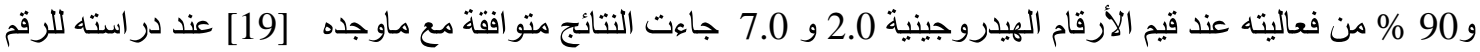

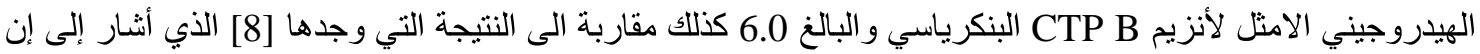

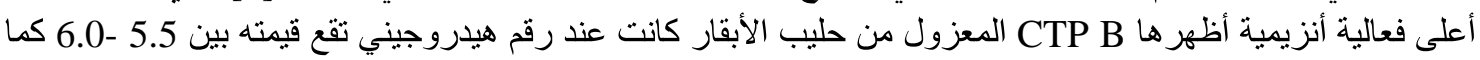

وجاءت النتيجة ضمن المدى الذي ذكره [7] للبروتييز ات السيستينية في الحليب ألبقري و الذي يقع بين 5.0 - 7.0.

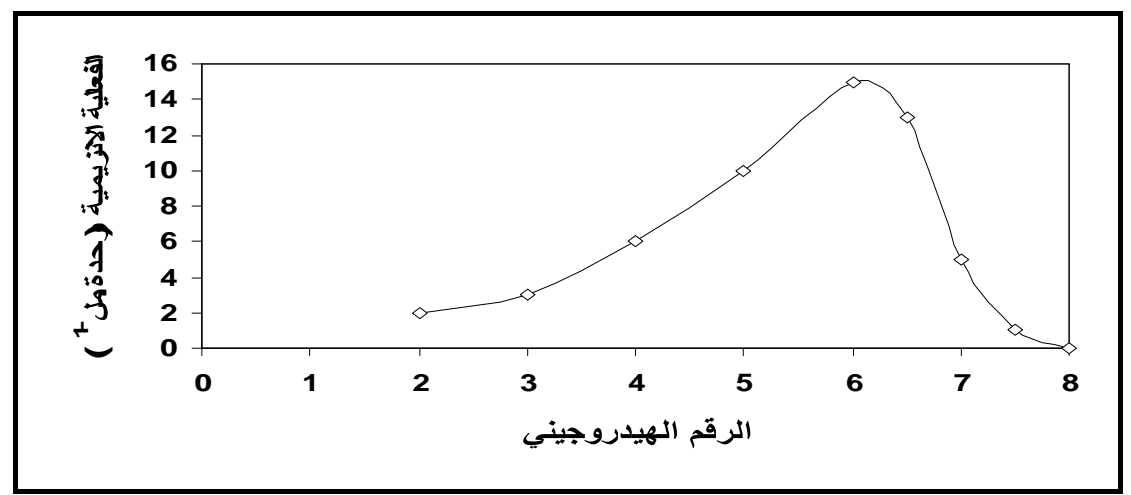

شكل (6) : منحنى الرقم الهيدروجيني الامثل لفعالية أنزيم القمة الرابعة F4 المعزول من خلايا PMN.

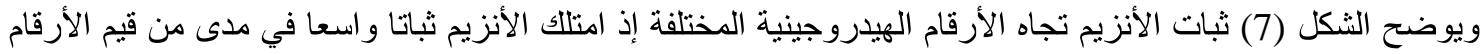

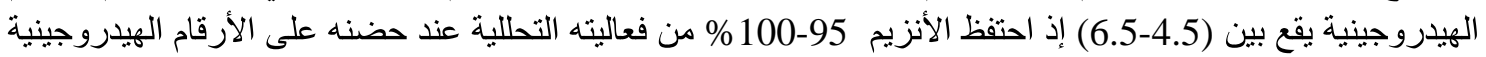

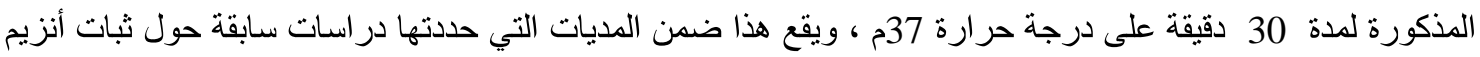

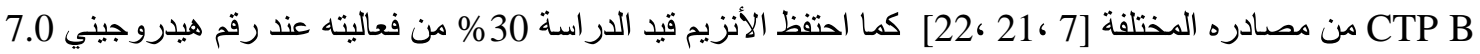

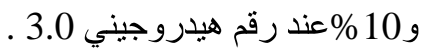




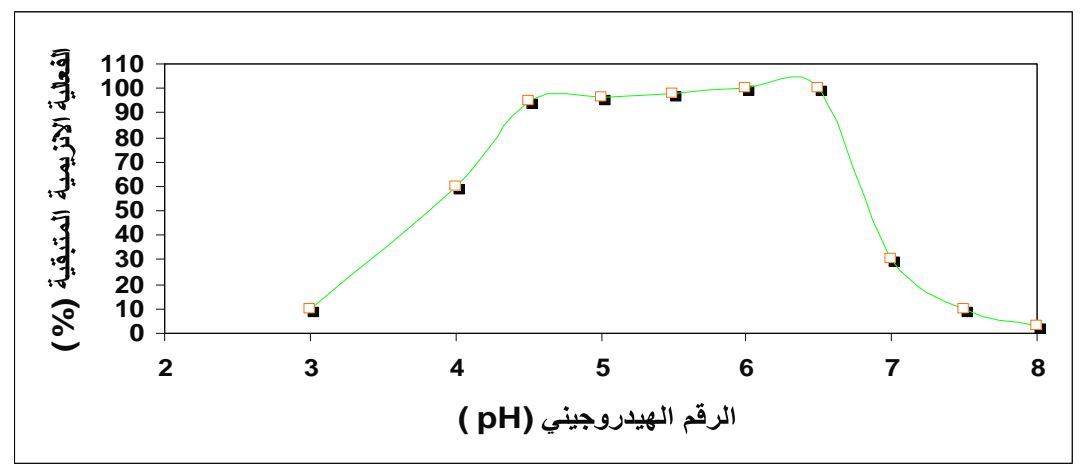

شكل(7) : منحنى الرقم الهيدروجيني الامثل لثبات أنزيم القمة الرابعة F4 المعزول من خلاياPMN

3. تعيين درجة الحرارة المثلى لفعالية وثبات الأنزيم

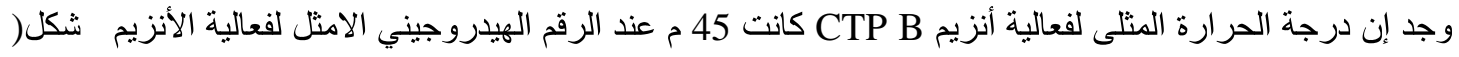

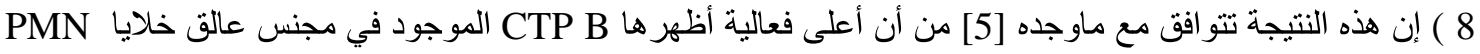

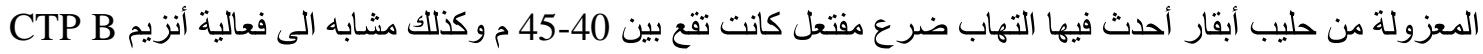

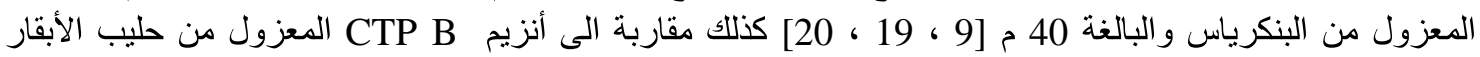

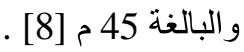

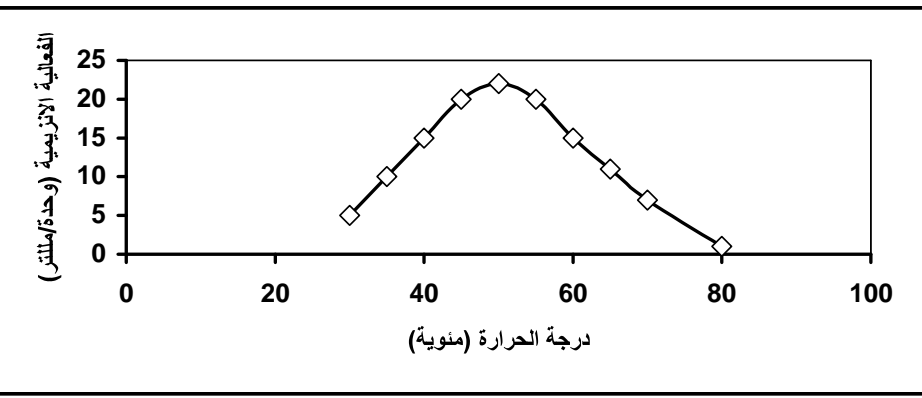

شكل (8) : منحنى درجة الحرارة المثلى لقعالية انزيم القمة الرابعة F4 المغزول من خلاياPMN

أما بالنسبة للثبات الحر اري للأنزيم فظهر في الثكل (9) إن الأنزيم يكون ثابت في مدى حراري 30-50 م حيث احتفظ

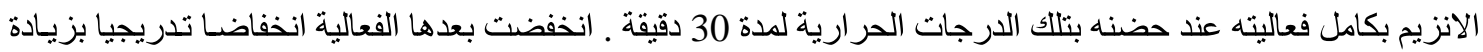

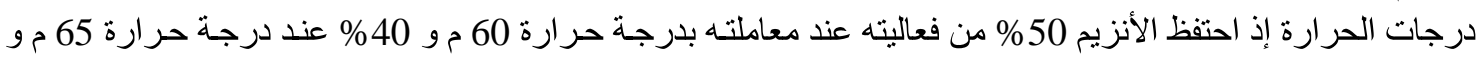

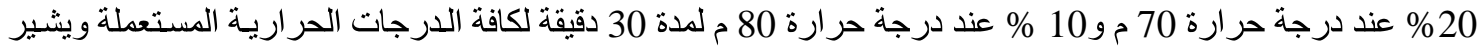

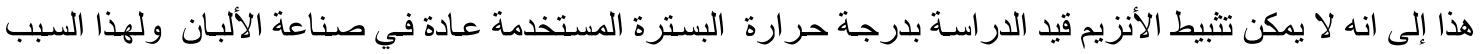

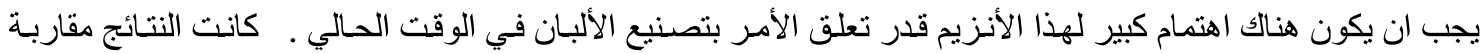

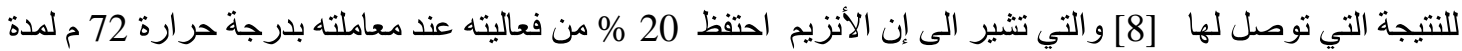

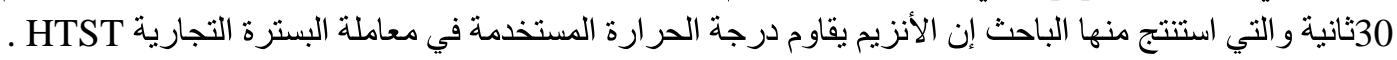




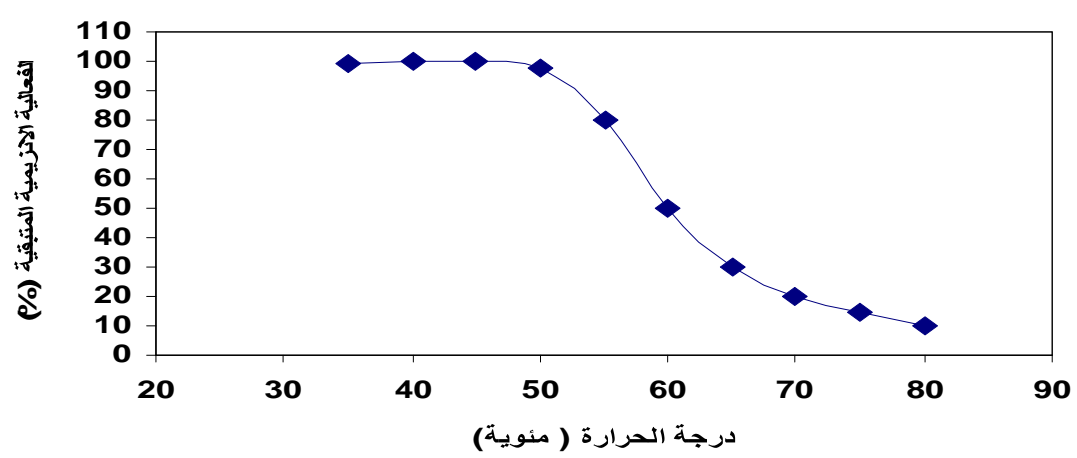

شكل (9) : تأثير درجة المعاملة الحرارية في فعالية انزيم القمة الرابعة F4 المعزول من خلايا PMN .

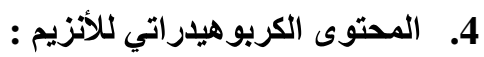

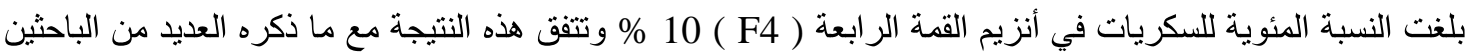

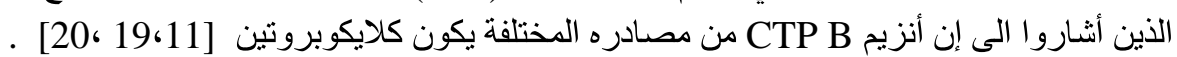

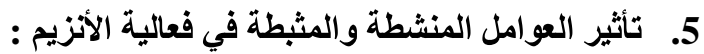

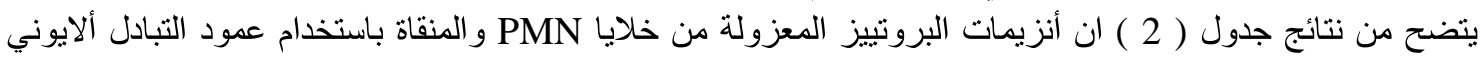

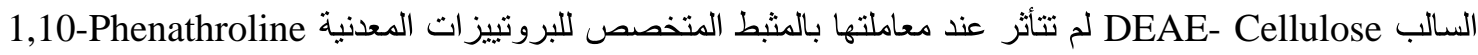

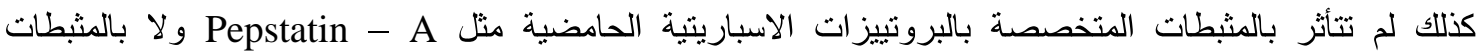

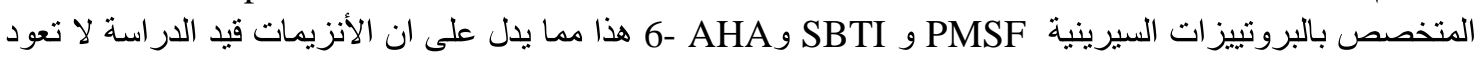

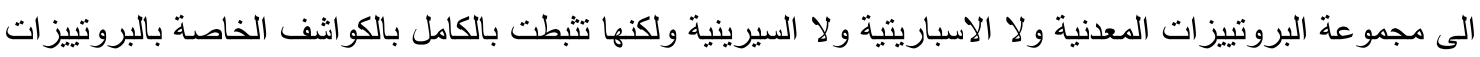

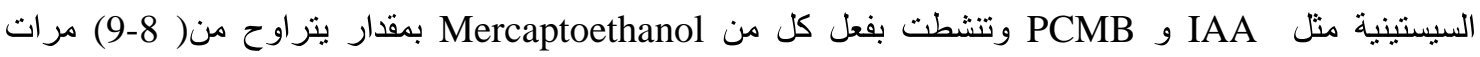

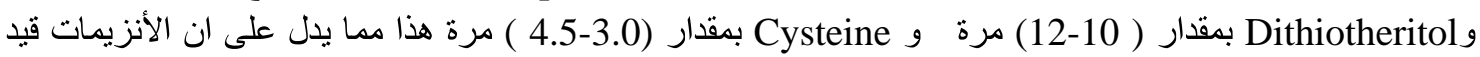

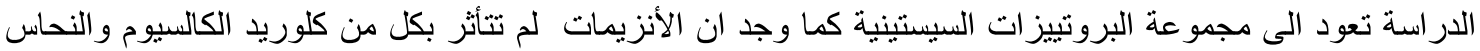

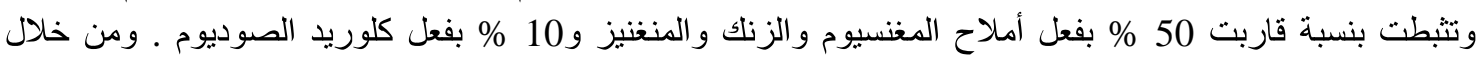

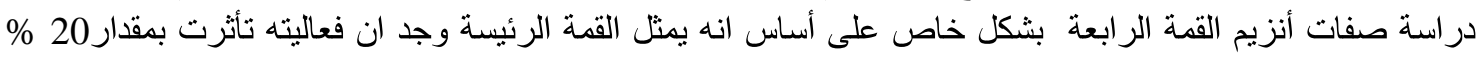

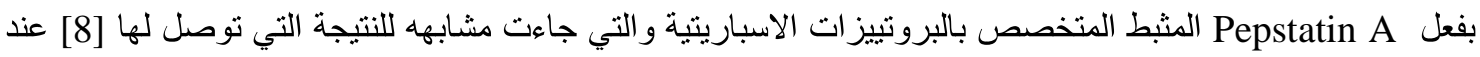

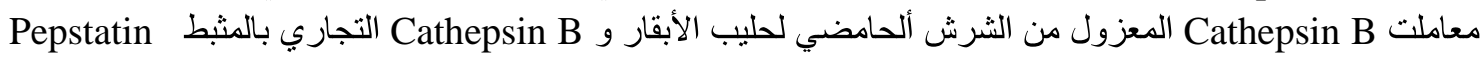
و واستتنج الباحث من ذللك ان هنالك علاقة معقدة بين البروتييزات السيستينية والاسبارتية وان Bepstatin A

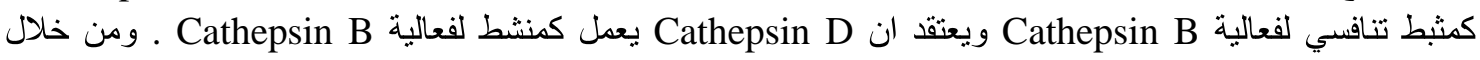

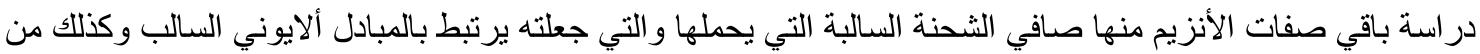

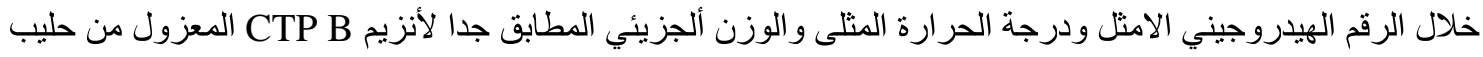

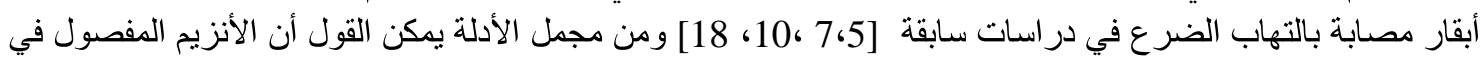

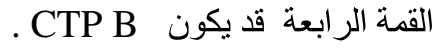


جدول (2) : تأثير بعض الكواشف في فعالية البروتييزات السيستينية المنقاة من خلايا المعزولة من حليب أبقار

\begin{tabular}{|c|c|c|c|c|c|c|}
\hline \multicolumn{4}{|c|}{ الفعالية المتبقية (\%) } & الت كن (مل هم ل م) & a & \\
\hline \multicolumn{4}{|c|}{100} & - & أنزيح غير معامل & \\
\hline F4 & F3 & $\mathrm{F} 2$ & F1 & & رقم الأنزيم المفصول & \\
\hline 80 & 100 & 100 & 100 & $1 \mathrm{mM}$ & Pepstatin A & 1 \\
\hline 95 & 100 & 100 & 110 & $1 \mathrm{mM}$ & PMSF & 2 \\
\hline 100 & 100 & 100 & 100 & $120 \mathrm{mM}$ & 6- AHA & 3 \\
\hline 0 & 0 & 0 & 0 & $0.1 \mathrm{mM}$ & Iodo acetic acid & 4 \\
\hline 0 & 0 & 0 & 0 & $1 \mathrm{mM}$ & PCMB & 5 \\
\hline 100 & 100 & 100 & 100 & $0.125 \mathrm{mg} / \mathrm{ml}$ & \multirow{2}{*}{ SBTI } & \multirow{2}{*}{6} \\
\hline 100 & 100 & 100 & 100 & $0.250 \mathrm{mg} / \mathrm{ml}$ & & \\
\hline 170 & 140 & 110 & 105 & $2 \mathrm{mM}$ & EDTA & 7 \\
\hline 1210 & 1000 & 1010 & 1100 & $10 \mathrm{mM}$ & DTT & 8 \\
\hline 100 & 107 & 103 & 100 & $10 \mathrm{mM}$ & 1,10-Phenathroline & 9 \\
\hline 900 & 813 & 950 & 800 & $10 \mathrm{mM}$ & 2- Mercaptoethanol & 10 \\
\hline 465 & 312 & 400 & 350 & $10 \mathrm{mM}$ & Cysteine & 11 \\
\hline 55 & 55 & 59 & 50 & $25 \mathrm{mM}$ & $\mathrm{ZnCl}$ & 12 \\
\hline 100 & 100 & 100 & 100 & $50 \mathrm{mM}$ & $\mathrm{CaCl}_{2}$ & 13 \\
\hline 100 & 100 & 100 & 100 & $5 \mathrm{mM}$ & $\mathrm{CuCl}_{2}$ & 14 \\
\hline 49 & 55 & 50 & 47 & $25 \mathrm{mM}$ & $\mathrm{MgCl}_{2}$ & 15 \\
\hline 60 & 58 & 60 & 59 & $25 \mathrm{mM}$ & $\mathrm{MnCl}_{2}$ & 16 \\
\hline 100 & 93 & 95 & 99 & $10 \mathrm{mM}$ & $\mathrm{NaCl}$ & 17 \\
\hline 90 & 90 & 90 & 90 & $50 \mathrm{mM}$ & $\mathrm{NaCl}$ & 18 \\
\hline
\end{tabular}

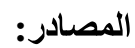

1. Considine, T. 2000. Role of somatic cell count and proteinases in dairy product quality. Ph. D. thesis .University Collage Cork, Ireland.

2. Fox, P. F; Kelly, A. L. (2006a). Indigenous enzymes in milk: Overview and historical aspects-Part 1. Int Dairy. J .10: 19-22.

3. Fox, P. F ; Kelly, A . L. (2006b) . Indigenous enzymes in milk: Overview and historical spects-Part 2. Int. Dairy J .10: 551-559.

4. Mehrazad, J. ; Desrosiers , G . ; Lauzone, K . ; Robitaille , G .; X . Zahao ,X. and Lacasse , P . 2005. Proteases involved in mammary tissue damage during endotoxin induced mastitis in dairy cows. J Dairy Sci .88:211 -222.

5. Moussaoui, F ; Michelutti ,L. ; LeRoux, Y. and Laurent, F . 2002. Mechanisms involved in milk endogenous proteolysis induced by lipopolysaccharide experimental mastitis. $\mathbf{J}$ Dairy Sci .85:2562 -2570.

6. Kaminogawa, S.; Yamauchi, K . (1972). Acid protease of bovine milk. Agric. Biol Chem. 36: $2351-2356$.

7. Suzuki, J. and Katoh, N. 1990. Cysteine protease in bovine milk capable of hydrolyzing casein as the substrates and elevation of the activity during the course of mastitis. Jap $\mathbf{J}$ Vet Sci. 52: 947 - 954.

8.Magboul, A. A.; Larsen, L.B. ; McSweeney, P.L.M. and Kelly, A.L. ( 2001). Cysteine protease activity in bovine milk. Int. Dairy. J. 11: 865 - 872. 
9. Haddadi, K. ; Mathieu, P. ; Moussaoui, F.; Fauren, G.; Vangroen, F. and Burvenich, F. G. (2006) . PMN and E.coli: Proteases involved in proteolysis of casein during experimental E.coli mastitis. Int Dairy. J .10:1016 -1022.

10. Mathieu, C. ; LeRoux,Y. ; Faure, G.C. ; Laurent, F. ; Bene,M.C. and Moussaoui , F. 2002. Enzymatic activities of Bovine peripheral blood leukocytes and milk polymorphonuclear neutrophils during intramammary inflammation caused by lipopolysaccharide Clinical and Diagnostic Laboratory Immunology.

11. Somers, J.; O'Brien, B.; Menney, w. and Kelly, A. L.2003. Heterogeneity of proteolytic enzyme activities in milk samples of different somatic cell count. J Dairy Res. 70: 45 -50.

12. International Dairy Federation. (2005) . Somatic Cell Count in milk. Their significance and recommended methods for counting. symposium on indigenous enzyme in milk , Cork , Ireland ,20 -22 April ,2005 .

13. Aworth, O.C. and Nakai, S. (1986). Extraction of milk clotting enzyme from Sodom Apple ( Calotropis procera) . J . Food Sci .51 (6) 1569-1570.

14. Bradford, M .M. 1976 . A rapid and sensitive method for the quantitation of microgram quantities of protein utilizing the principle of protein - dye binding. Analytical Bioch. $72: 248-254$.

15. Laemmli, U. K. 1970. Cleavage of structural proteins during the assembly of the head of bacteriophage T4. Nature .227: $680-690$.

16. Dubiose, M. ; K. A. Gilles; J. K. Hamiton ; P. A. Robers and F. Smith. 1956 . Colorimetric method for determination of sugars and related substances. Anal Chem.228:350 -356.

17. Pharmacia Fine Chemical AB Publication. (1980). Ion - exchange chromatography. Principle and methods. Uppsala.

18. O’Driscoll, B. M.; Rattray, F. P.; McSweeney, P .H. L. and Kelly, A. L. (1999). Protease activites in raw milk determined using synthetic heptapeptides substrate. J. Food Sci. 64:606 -611.

19. Kirschke, H.; Barrett, A. J. and Rawling, N. D.( 1998). Lysosomal cysteine proteinases. , 2nd ed, Oxford University press.

20. Katunuma, N. and Kominani, E. ( 1983) . Structure and function of lysosomal thiol proteinases and their endogenous inhibitors Curr.Top.Cell .Regel .27:345.

21. Bird, J .W. C.; Carter, J.; Triemer, R. E.; Brooks, R .M. and Spnier, A. M. (1980). Proteinases in cardiac and skeletal muscle .Fed .Proc. Fed .Am Soc Exp Biol .39:20 -25.

22. Larsen, L. B.; McSweeney, P.L.H. ; Hayes, M.G. ; Andersen, J.B. ; Ingvartsen, K.I. and Kelly, A.L. 2006 . Variation in activity and heterogeneity of bovine milk protease with stage of lactation and somatic cell count. Int Dairy. J .17:1-8. 